\title{
EDUCAÇÃO A DISTÂNCIA NA ENGENHARIA CIVIL: UMA PROPOSTA DE FORMAÇÃO ONLINE EM GESTÃO DE OBRAS
}

Lilian Segnini Rodrigues - lilian.rodrigues@docente.unip.br

Universidade Paulista UNIP - Instituto de Ciências Exatas e Tecnologia - ICET

Av. Alberto Benassi, 200 - Parque das Laranjeiras

CEP 14.848-300 - Araraquara - SP

Itamar Aparecido Lorenzon - itamar@ufscar.br

Universidade Federal de São Carlos - Centro de Ciências Exatas e de Tecnologia - CCET

Rod. Washington Luís, SP $310 \mathrm{~km} 235$

CEP 13.565-905 - São Carlos - SP

Resumo: Este artigo tem como objetivo apresentar uma proposta de formação online em Gestão de Obras, que antes era oferecida na modalidade presencial e que, em virtude da pandemia, precisou ser adaptada para a nova realidade. A adaptação deste curso para a modalidade online se mostrou promissora e, com isso, surge a possibilidade de implantação definitiva do curso neste formato. Trata-se, portanto, de um estudo de caso, com abordagem qualitativa. Conclui-se que, embora o curso de Gestão de Obras no formato presencial esteja consolidado, o oferecimento de uma opção online traz grandes benefícios para o reconhecimento deste curso, já que o torna mais acessível, seja em função da mobilidade, seja em função do custo, que deverá ser menor do que aquele da modalidade presencial.

Palavras-chave: Ensino a Distância. Formação online. Engenharia Civil. Gestão de Obras.

\section{INTRODUÇÃO}

Mudanças na sociedade contemporânea, acompanhadas de fenômenos como a globalização, o avanço tecnológico, a popularização do acesso à internet e dos smartphones, o consequente aumento da mobilidade, dentre outros, são fatores que contribuem para um cenário ideal para a educação a distância - $\mathrm{EaD}$, que tem crescido cada vez mais em todo mundo.

De acordo com os dados do Censo da Educação Superior de 2018 realizado pelo Inep (2019, p. 15), "o aumento no número de ingressantes em 2018 foi sustentado pelo significativo aumento na nos cursos na modalidade a distância, compensando a queda registrada nos cursos presenciais". Segundo o Inep, o aumento do número de ingressantes entre 2017 e 2018 é ocasionado, exclusivamente, pela modalidade a distância, que teve uma variação positiva de $27,9 \%$ entre esses anos, enquanto nos cursos presenciais houve uma variação de $-3,7 \%$.

Os dados do Inep corroboram com a vasta literatura da educação a distância no Brasil, que demonstram que essa é uma modalidade, na visão de Lourenzo (2019), que ocupa um espaço cada vez maior entre os modelos de ensino-aprendizagem disponíveis para as pessoas.

A característica fundamental da $\mathrm{EaD}$ reside no fato de que, nesta modalidade, professores e alunos estão separados fisicamente no espaço e/ou no tempo, fazendo-se necessário o uso de tecnologias de informação e comunicação (VALENTE; MORAN; ARANTES, 2011), o que 
facilita a flexibilidade dos estudantes, seja no aspecto de autonomia para o estudo ou em relação à impossibilidade de realizar um curso presencial em outra localidade.

Nesse sentido, Kenski (2012) destaca que os espaços educacionais, em especial os modelos de ensino-aprendizagem que aconteciam somente em espaços físicos, conhecidos como salas de aula, vem se transformando em virtude da revolução digital. Antes, os estudantes precisavam se locomover até estes lugares, bem como à locais considerados do saber, como bibliotecas, campus, laboratórios etc., o que, na modalidade $\mathrm{EaD}$, não se faz necessário.

Diante do potencial que a EaD vem demonstrando ao meio acadêmico, pesquisas que envolvem propostas de implantação de cursos $\mathrm{EaD}$ são relevantes para a literatura, o que, por si só, justifica essa pesquisa. Em especial nas Engenharias, Patella (2015) aponta que ainda há certa resistência dos órgãos regulamentadores, como o Conselho Regional de Engenharia e Agronomia - CREA, que alegam que a EaD não contempla tudo o que o ensino presencial oferece. No entanto, essa barreira ideológica vem sendo quebrada e os dados da Associação Brasileira de Educação a Distância apontam que já existem mais de 100 cursos de engenharia sendo oferecidos nesta modalidade em diversas instituições de ensino do país.

Além do notório crescimento da EaD no Brasil e no mundo, que já vem ocorrendo há alguns anos em virtudes de vários fatores, outro fato fez essa modalidade ganhar mais adeptos: a pandemia do novo coronavírus (Covid 19). Com reflexos mundiais, principalmente no ano de 2020, muitas instituições de ensino se viram obrigadas a recorrer à tecnologia e à EaD para manterem aulas e cursos. Não foi diferente no curso de Gestão de Obras oferecido pelo Departamento de Engenharia Civil da Universidade Federal de São Carlos, que antes era oferecido na modalidade presencial e que, em virtude da pandemia, precisou ser adaptado para a nova realidade, na modalidade online.

Tal formato vem sendo oferecido a uma turma de alunos desde julho/2020 deve ser finalizada em fevereiro/2021, porém, surgiu a ideia e a possibilidade de implantação definitiva deste curso na modalidade EaD. Desta forma, o objetivo deste artigo é apresentar uma proposta de formação online em Gestão de Obras.

O artigo está estruturado em cinco seções, sendo essa introdução sua primeira seção. Em seguida uma breve contextualização da Educação a Distância, em especial no Brasil e na área da engenharia (2), acompanhada da metodologia (3), da apresentação da proposta de formação online em Gestão de Obras (4) e sua discussão nas considerações finais (5).

\section{EDUCAÇÃO À DISTÂNCIA}

Em todo o mundo, as instituições de ensino têm sido estimuladas a aperfeiçoarem e expandirem suas formas de ensino-aprendizagem em virtude de novas necessidades criadas pela globalização. Neste sentido, a Educação a Distância - EaD se tornou uma forma eficaz de atender às novas demandas impostas por uma sociedade em evolução. Neste modelo, o conhecimento é transferido sem que haja, necessariamente, espaço físico, como salas de aulas (CASSUNDÉ; CASSUNDÉ JR, 2012).

Em virtude dos resultados promissores, a partir da década de 1970 a EaD se consolidou em todo o mundo como opção pedagógica. De acordo com Mauro et al. (2017, p. 121) "no ensino superior, o desenvolvimento da $\mathrm{EaD}$ vem ocorrendo nas cinco últimas décadas, porém ressaltase que a partir dos anos de 1990 diversos projetos foram inserindo a modalidade como uma ferramenta geradora da democratização do ensino superior". Assim, a EaD é uma modalidade de ensino que permite a ascensão de oportunidades para muitas pessoas, por ser um modelo mais flexível e menos dispendioso. 
De acordo com Freitas (2005), esta modalidade de ensino se torna importante à medida que possibilita o acesso de novas camadas da sociedade na busca por educação e qualificação profissional, tendo em vista as rápidas mudanças e transformações que ocorrem o tempo todo em todas as áreas do conhecimento. Para a autora, a EaD não é recente, já que tem sido utilizada desde 1728 nos EUA e desde 1840 na Inglaterra, porém, nestes períodos, o modelo sofreu muito preconceito por parte de acadêmicos que acreditava que esta forma de ensino era de baixa qualidade. A autora esclarece, por fim, que a $\mathrm{EaD}$ somente ganhou respeito após a implantação da Universidade Aberta da Inglaterra no final do século XX e que hoje é um modelo muito respeitado na academia mundial.

Alves (2011) afirma que a EaD, além de estar rompendo barreiras e criando um espaço próprio, também é uma possibilidade de complementação da modalidade presencial, proporcionando conveniências que seriam difíceis ou impossíveis de serem alcançadas no ensino presencial em virtude da sua magnitude e extensa abrangência, não só no Brasil, mas em todo o mundo. Para além das questões que envolvem a flexibilidade e mobilidade, a EaD é uma modalidade capaz de estimular a criatividade, a funcionalidade cognitiva e a maturidade intelectual do estudante, que poderá desenvolver competências técnicas e comportamentais, por meio da participação, criação, inovação e reflexão (MORAN, 2007).

Para Maia e Matar (2007, p. 6), a EaD é "uma modalidade de educação em que professores e alunos estão separados, planejada por instituições e que utiliza diversas tecnologias de comunicação". Os autores destacam três pontos nesta definição: (1) separação no espaço, já que os estudantes e os professores/instrutores não estão fisicamente no mesmo lugar, (2) separação no tempo, pois as atividades podem ser assíncronas, onde cada estudante a realiza no tempo que lhe for mais conveniente e (3) planejamento, pois é uma modalidade de ensino que precisa ser planejada por uma instituição de ensino, com acompanhamento e supervisão de coordenadores, professores e tutores.

\subsection{Educação a distância no Brasil}

Segundo Giolo (2018, p. 74), a EaD no Brasil é um fenômeno datado do século XXI, já que, para o autor, quaisquer experiências anteriores a este século são pouco significativas, consideradas meros experimentos de um modelo que hoje está bastante consolidado no país. "Então, de imediato, delimitemos o sentido do termo "educação a distância" ao fenômeno recente e à volumosa presença da modalidade a distância na educação formal, usufruindo das mesmas prerrogativas que a modalidade presencial".

Nos relatórios do Censo da Educação Superior do Instituto de Estudos e Pesquisas Educacionais Anísio Teixeira - Inep, a EaD começou a aparecer no ano de 2000, exclusivamente em instituições públicas. Na iniciativa privada os dados estatísticos começaram a surgir nos relatórios a partir do ano de 2002. A década anterior, 1990, serviu de base para que a $\mathrm{EaD}$ adquirisse corpo e chegasse ao patamar dos dias atuais. Esta década foi marcada por iniciativas de várias naturezas, especialmente de ordem legal e institucional. Com relação às iniciativas de natureza legal, temos o caso da Lei de Diretrizes e Bases - LDB (Lei $n^{\circ}$ 9.394/1996), do Decreto $n^{\circ}$ 2.494/1998 (alterado pelo Decreto $n^{\circ}$ 2.561/1998) e da Medida Provisória $\mathrm{n}^{\circ}$ 1.477-39/1997. Já com relação às iniciativas de natureza institucional, pode-se citar a criação da Subsecretaria de Programas de Educação a Distância, dentro da Secretaria de Comunicação Social da Presidência da República, em 1995, e a criação da Secretaria de Educação a Distância (SEED) do Ministério da Educação, em 1996 (GIOLO, 2018).

Após a EaD ser introduzida no Brasil, a partir de 2000, outras várias iniciativas de ordem legal, institucional, dentre foram, foram tomadas. Uma das iniciativas mais importantes foi a 
criação do Sistema Universidade Aberta do Brasil - UAB, em 08 de junho de 2006 via decreto $\mathrm{n}^{\circ}$ 5.800. Esse sistema "é voltado para o desenvolvimento da modalidade EaD com a finalidade de expandir e interiorizar a oferta de cursos e programas de educação superior no país" (COSTA, 2017, p. 70).

Com relação aos números, o que aponta o último Censo da Educação Superior feito pelo Inep é que a $\mathrm{EaD}$ é uma modalidade que têm crescido muito no Brasil nos últimos anos, em percentual bastante superior ao crescimento da modalidade presencial. O gráfico 1 ilustra a evolução das duas modalidades em longo dos anos.

Gráfico 1 - Número de ingressos em cursos de graduação, por modalidade de ensino - Brasil - 2008-2018

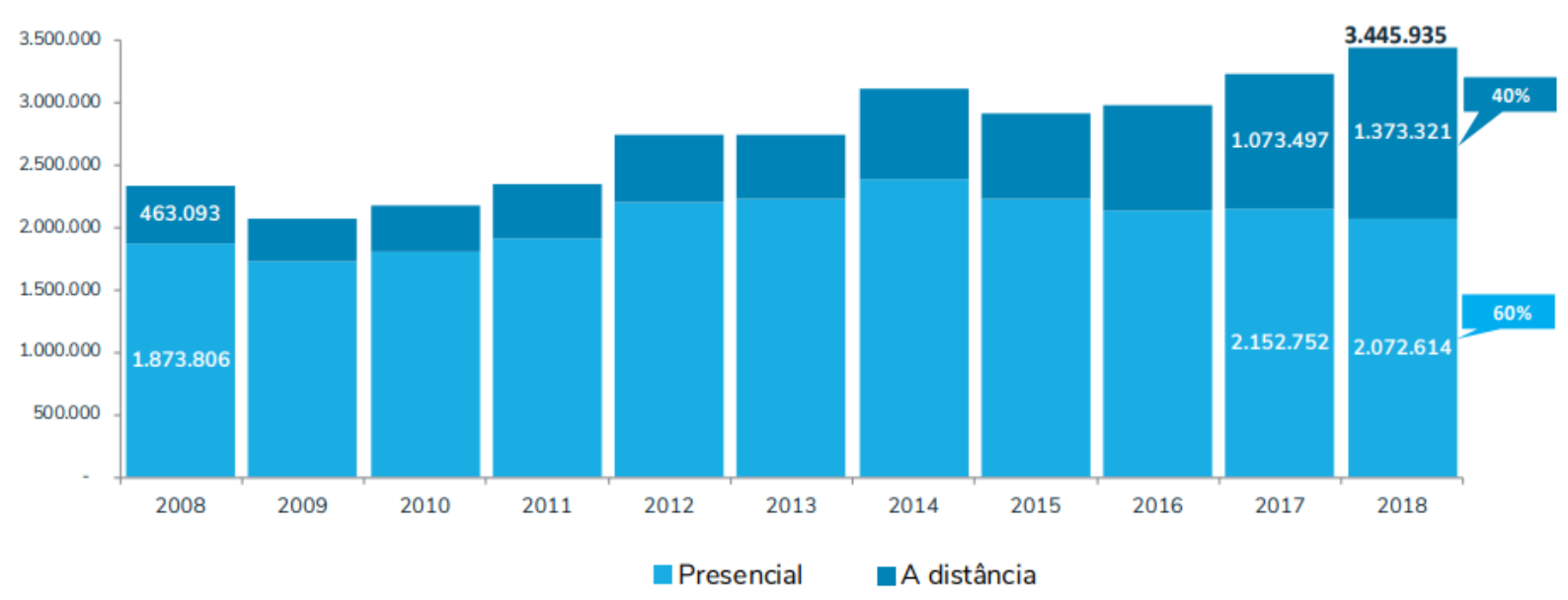

Fonte: Brasil, Inep (2019, p. 15)

Entre 2008 e 2018, o número de ingressos variou positivamente $10,6 \%$ nos cursos de graduação presencial e triplicou $(196,6 \%)$ nos cursos à distância. Enquanto a participação percentual dos ingressantes em cursos de graduação a distância em 2008 era de 19,8\%, essa participação em 2018 foi para quase 40\% (BRASIL. INEP, 2019)

\subsection{Educação a distância no ensino de engenharia}

Andrade, Brito e Oliveira (2012) afirmam que o ensino de engenharia tem sido objeto de várias discussões e reformulações Apesar das várias razões para as discussões acerca do ensino em engenharia, o autor destaca o impacto do conhecimento tecnológico atualizado e dinâmico, afirmando que esse deve ser o objetivo central do ensino em engenharia. Sendo assim, novas metodologias de ensino-aprendizagem estão sendo levadas em consideração, como é o caso da $\mathrm{EaD}$.

Azambuja, Grimoni e Cury (2014) realizaram um estudo sobre o uso de Internet Protocol Television - IPTV (sistema em que um serviço de televisão digital é entregue pela rede Internet Protocolo - IP) como uma nova proposta de modalidade para a educação a distância no ensino de engenharia, mostrando o quão promissor pode ser esta modalidade na formação de engenheiros, uma vez que pode ajudar a reduzir as distâncias no ensino de engenharia.

Tomando como exemplo, um profissional que possa estar em uma plataforma de petróleo ao fazer o uso de uma rede IP, pode oferecer uma aula para um grupo determinado de alunos/profissionais ou para uma universidade, abrindo um novo campo para reduzir as distâncias no ensino de engenharia e trazer a experiência da 
prática para a sala de aula em tempo real e atual (um engenheiro de uma plataforma de petróleo tem muita experiência da teoria aplicada na solução dos problemas reais) (AZAMBUJA, GRIMONI E CURY, 2014, p. 198).

Anualmente, desde 2008, a Associação Brasileira de Educação à Distância - Abed, divulga o Censo EaD.BR, que se trata de um relatório analítico da aprendizagem a distância no Brasil. No relatório publicado em 2010, referente aos números de 2008, o número total de cursos a distância no Brasil na temática 'Engenharias e Máquinas' era de 33. Com relação à matrícula em cursos de engenharia na modalidade $\mathrm{EaD}$, nas instituições credenciadas à $\mathrm{ABED}$, esse número foi de apenas 5 em 2008. No último censo divulgado pela Abed, com relação aos números de 2018, o número de matrículas foi de 14.405. Ou seja, de 2008 a 2018, o aumento no número de matrículas em cursos de engenharia $\mathrm{EaD}$ foi de mais de $288.000 \%$. Com relação à oferta de cursos regulamentados, em 2018 havia o oferecimento de 46 cursos totalmente a distância e 103 cursos semipresenciais (ABED, 2010; 2019).

$\mathrm{O}$ que se pode concluir acerca da $\mathrm{EaD}$ no ensino de engenharia é que se trata de uma modalidade bastante promissora, não apenas por cumprir o seu principal papel, que é a democratização do ensino, como fornecer à área de engenharia novas possibilidades de ensino e novas ferramentas educacionais, ligadas à tecnologia da informação e comunicação, como é o caso da IPTV, e-learning, gamificação, dentre outras.

\section{METODOLOGIA}

Esta pesquisa é classificada como descritiva, com abordagem qualitativa. Com relação aos procedimentos técnicos, trata-se de um estudo de caso. Segundo Yin (2015), o estudo de caso é uma investigação empírica de um fenômeno contemporâneo dentro de um contexto da vida real, sendo que os limites entre o fenômeno e o contexto não estão claramente definidos. O caso em questão é uma proposta de implantação de uma formação online em Gestão de Obras, oferecida pelo Departamento de Engenharia Civil da Universidade Federal de São Carlos.

Para a interpretação dos dados, será utilizado o modelo de análise qualitativa proposto por Miles e Huberman (1994), que se resume em três momentos: (1) a redução dos dados, (2) a apresentação dos dados e (3) as conclusões. A redução se refere ao processo de selecionar, simplificar e organizar todos os dados obtidos durante a investigação. O que se pretende com esse procedimento é que o grande acúmulo de dados brutos seja reduzido ao essencial para proporcionar sua análise e interpretação. Neste artigo, a redução dos dados se refere a organização de todos as informações acerca da proposta de formação online em Gestão de Obras, como ferramentas, conteúdo programático, atividades, avaliação, certificação etc.

A apresentação dos dados diz respeito ao momento em que a informação é organizada e compactada para rápida verificação do que se trata o estudo: identificar o tema e os dados encontrados. Assim, essa etapa possibilita a análise sistemática das semelhanças e diferenças e seu inter-relacionamento. Esta apresentação é feita na seção 4 deste artigo. O terceiro e último momento corresponde às conclusões das informações recolhidas, organizadas e compactadas, ou seja, busca-se a identificar o significado dos dados, suas regularidades, padrões e explicações. As conclusões acerca da proposta de implantação de uma formação online em Gestão de Obras, bem como seu potencial em contribuir com um modelo para o ensino em engenharia, são apresentadas na seção 5. 


\section{PROPOSTA DE FORMAÇÃO ONLINE EM GESTÃO DE OBRAS}

As incertezas que vive o setor da construção civil fazem com as empresas procurem por profissionais mais bem qualificados de maneira atender as demandas do mercado quanto à qualidade e produtividade. Em contrapartida, verifica-se uma escassez de profissionais devidamente qualificados no mercado de trabalho que consiga suprir a atual e futura demanda. Neste contexto, as empresas construtoras estão investindo na qualificação de seus profissionais, também profissionais autônomos buscam aperfeiçoamento de seus conhecimentos como forma de inserção e destaque no mercado de trabalho.

O Curso de Aperfeiçoamento em Gestão de Obras foi idealizado para atender essa demanda do mercado por meio de uma atividade de Extensão que consiste na transferência de conhecimentos para engenheiros, arquitetos e tecnólogos, professores e outros profissionais desta área de atuação em temas afetos à gestão de obras, abordando Planejamento e controle de obras, Orçamento na construção civil, Produtividade da mão de obra e no uso de recursos físicos e Gestão dos resíduos de obras.

Esta capacitação profissional traz benefícios direto à melhoria da produtividade nas execuções das obras, além de possibilitar maior integração entre os docentes envolvidos com o setor produtivo. O Curso está inserido no Programa: Melhoria da Qualidade e Produtividade na Construção Civil. Os temas abordados no curso são de extrema relevância para o desenvolvimento de competências com foco em melhoria da competitividade, e estão intimamente relacionados com o apresentado no curso de graduação em engenharia civil da UFSCar, assim como estão alinhavados com disciplinas e pesquisas desenvolvidas no âmbito do Programa de Pós-Graduação em Estruturas e Construção Civil da UFSCar. A formação dos profissionais é feita em 4 módulos, conforme Tabela 1.

Tabela 1 - Módulos do curso de Gestão de Obras/UFSCar

\begin{tabular}{|c|c|c|}
\hline Módulo & $\mathbf{C H}^{*}$ & Conteúdo Programático \\
\hline $\begin{array}{l}1 \text { - Produtividade no uso } \\
\text { dos recursos físicos }\end{array}$ & 24 horas & $\begin{array}{l}\text { Importância da medição do desempenho no uso dos recursos físicos } \\
\text { nos canteiros de obras e caminhos possíveis para a implementação de } \\
\text { um sistema de gestão no uso dos recursos físicos nos canteiros de } \\
\text { obras. }\end{array}$ \\
\hline $\begin{array}{l}2 \text { - Orçamento na } \\
\text { Construção Civil }\end{array}$ & 32 horas & $\begin{array}{l}\text { Etapas da orçamentação, grau de detalhe dos orçamentos, precisão } \\
\text { dos orçamentos e as funções do orçamentista e o setor de orçamentos } \\
\text { nas empresas. }\end{array}$ \\
\hline $\begin{array}{l}3 \text { - Planejamento e } \\
\text { Controle de Obras }\end{array}$ & 48 horas & $\begin{array}{l}\text { Níveis do planejamento. Estratégico, Tático e Operacional, } \\
\text { detalhamento do cronograma, visualização por meio da Estrutura } \\
\text { analítica do projeto (EAP) / Work Breakdown Structure (WBS), } \\
\text { elaboração de cronograma físico-financeiro. }\end{array}$ \\
\hline $\begin{array}{l}\text { 4- Qualidade e Resíduos } \\
\text { na Construção civil }\end{array}$ & 24 horas & $\begin{array}{l}\text { Definição e classificação dos resíduos da construção civil, Gestão dos } \\
\text { RCC nas cidades: coleta, transporte, tratamento e destinação final. }\end{array}$ \\
\hline
\end{tabular}

Fonte: Elaborada pelos autores (2020)

Além disso, o Curso de Gestão de Obras consta com atividades como: Preparação para o trabalho final (44 horas) e Apresentação dos trabalhos práticos (16 horas). A atividade Preparação para o trabalho final tem um caráter remoto, o que soma um total de 188 horas.

No formato presencial o Curso foi desenvolvido para o campus São Carlos da UFSCar, com aulas aos sábados, das $8 \mathrm{~h}$ às $17 \mathrm{~h}$ e intervalo de uma hora para o almoço. Sempre teve início em meados de março e o término em meados de novembro. A primeira turma do Curso foi em 2013 e a oferta é anual, sendo que nos anos 2015 e 2019 foram divididas em duas turmas. 
"Os desafios para formar hoje o engenheiro do amanhã"

A tabela 2 apresenta a quantidade de alunos(as) por ano/turma no curso de Gestão de Obras.

Tabela 2 - Quantidade de alunos(as) por ano no curso de Gestão de Obras/UFSCar

\begin{tabular}{ccccccccc}
\hline Ano & $\mathbf{2 0 1 3}$ & $\mathbf{2 0 1 4}$ & $\mathbf{2 0 1 5}$ & $\mathbf{2 0 1 6}$ & $\mathbf{2 0 1 7}$ & $\mathbf{2 0 1 8}$ & $\mathbf{2 0 1 9}$ & $\mathbf{2 0 2 0}$ \\
\hline Alunos & 14 & 30 & 55 & 40 & 48 & 26 & 59 & 35 \\
\hline
\end{tabular}

Fonte: Elaborada pelos autores (2020)

Com a pandemia e a suspensão das atividades acadêmicas presenciais na UFSCar houve a necessidade de adaptação do formato presencial para o formato online. Os alunos foram consultados e praticamente todos concordaram, apenas alguns poucos argumentaram preferir o formato presencial. Foi necessário um novo calendário de aulas, com a mesma carga horária e o mesmo conteúdo programático. Com o novo prazo foi possível abrir as inscrições para o formato online. O término do curso, que inicialmente estava previsto para novembro/2020 passou para fevereiro/2021, utilizando-se os seguintes formatos e tecnologias: Google Meeting e Classroom. No ambiente Classroom é possível criar repositório de materiais, como aulas, artigos, manuais técnicos etc. É possível armazenar os exercícios desenvolvidos em aula. No desenvolvimento das aulas a interação entre o docente e os alunos pode ser meio de conversa ou por meio do chat de dúvidas. Esse canal tem a vantagem da dúvida e a resposta ficarem armazenadas.

O curso, neste formato online, que foi adaptado para a nova realidade imposta pela pandemia do coronavírus, mostrou-se bastante promissor e tem agradado o público-alvo, que são os alunos. Desta forma, uma nova possibilidade surgiu, que é a implantação efetiva deste curso na modalidade EaD. Esta modalidade de curso deve ser oferecida como mais uma opção além da presencial, com característica mais acessível ao público-alvo, seja em função do custo, que deve ser menor, seja em função da mobilidade, já que poderá abranger estudantes das mais variadas localidades.

No entanto, para que seja implantado definitivamente na modalidade EaD, o curso deverá passar por alterações de conteúdo, atividades e carga horária. A carga horária não poderá ser reduzida em função da obrigatoriedade legal para que o curso seja considerado um aperfeiçoamento. É essencial dividir a carga horária dos módulos em atividades síncronas (aulas online/lives) e assíncronas (atividades). Além disso, há a necessidade de um módulo introdutório que deverá abordar noções relacionadas ao ensino a distância, o que aumentará a carga horária total para 200 horas. Outra necessidade é a atuação de tutores, que farão o papel de mediador entre os(as) alunos(as) e os(as) docentes, bem como serão responsáveis por mediar fóruns e tirar as dúvidas pontuais. Todas as atividades assíncronas passarão pela revisão de docentes ou tutores e serão oferecidos feedbacks para os(as) alunos(as), que devem obedecer ao modelo de feedback formativo.

Além destas adaptações, será necessária a aquisição de um domínio de LMS - Learning Management System (ou Sistema de Gestão de Aprendizagem). Apesar do Google Classroom ser uma boa ferramenta, o LMS faz a gestão completa de um curso na modalidade EaD, inclusive gerenciar a evolução da aprendizagem dos alunos. Um dos mais utilizados em todo mundo é o Moodle, que também é utilizado em vários outros cursos oferecidos pela UFSCar, principalmente aqueles que são oferecidos em parceria com a Secretaria Geral de Educação a Distância - SEaD/UFSCar. Assim, a aquisição de um domínio do Moodle se mostra a solução mais apropriada para este curso. A Tabela 3 apresenta a proposta de componentes, atividades, carga horária e conteúdo programático para a modalidade EaD definitiva do curso de Gestão de Obras. 
Tabela 3 - Proposta de Módulos/CH/Conteúdo Programático do curso EaD em Gestão de Obras/UFSCar

\begin{tabular}{|c|c|c|c|}
\hline Componente & Composição & CH* & Conteúdo Programático \\
\hline \multirow{2}{*}{$\begin{array}{l}\text { 1. Introdução ao } \\
\text { Ensino a Distância }\end{array}$} & $\begin{array}{l}\text { Aulas online } \\
\text { (conteúdo) }\end{array}$ & 6 horas & \multirow{2}{*}{$\begin{array}{l}\text { Navegação no ambiente virtual de aprendizagem, noções } \\
\text { básicas de netiqueta e boas práticas, gestão do tempo, } \\
\text { organização da agenda, participação em fóruns. }\end{array}$} \\
\hline & $\begin{array}{l}\text { Fórum de } \\
\text { discussão }\end{array}$ & 6 horas & \\
\hline \multirow{2}{*}{$\begin{array}{l}\text { 2. Produtividade no } \\
\text { uso dos recursos } \\
\text { físicos }\end{array}$} & $\begin{array}{l}\text { Aulas online } \\
\text { (conteúdo) }\end{array}$ & 12 horas & \multirow{2}{*}{$\begin{array}{l}\text { Importância da medição do desempenho no uso dos } \\
\text { recursos físicos nos canteiros de obras e caminhos } \\
\text { possíveis para a implementação de um sistema de gestão } \\
\text { no uso dos recursos físicos nos canteiros de obras. }\end{array}$} \\
\hline & $\begin{array}{l}\text { Atividades } \\
\text { técnica }\end{array}$ & 12 horas & \\
\hline \multirow{2}{*}{$\begin{array}{l}\text { 3. Orçamento na } \\
\text { Construção Civil }\end{array}$} & $\begin{array}{l}\text { Aulas online } \\
\text { (conteúdo) }\end{array}$ & $16 \mathrm{~h}$ & \multirow{2}{*}{$\begin{array}{l}\text { Etapas da orçamentação, grau de detalhe dos orçamentos, } \\
\text { precisão dos orçamentos e as funções do orçamentista e o } \\
\text { setor de orçamentos nas empresas. }\end{array}$} \\
\hline & $\begin{array}{l}\text { Atividades } \\
\text { técnica }\end{array}$ & 161 & \\
\hline \multirow{2}{*}{$\begin{array}{l}\text { 4. Planejamento e } \\
\text { Controle de Obras }\end{array}$} & $\begin{array}{l}\text { online } \\
\text { eúdo) }\end{array}$ & $24 \mathrm{l}$ & \multirow{2}{*}{$\begin{array}{l}\text { Níveis do planejamento. Estratégico, Tático e } \\
\text { Operacional, detalhamento do cronograma, visualização } \\
\text { por meio da Estrutura analítica do projeto (EAP) / Work } \\
\text { Breakdown Structure (WBS), elaboração de cronograma } \\
\text { físico-financeiro. }\end{array}$} \\
\hline & $\begin{array}{l}\text { Atividades } \\
\text { técnica }\end{array}$ & 24 ho & \\
\hline \multirow{2}{*}{$\begin{array}{l}\text { 5. Qualidade e } \\
\text { Resíduos na } \\
\text { Construção civil }\end{array}$} & $\begin{array}{l}\text { Aulas online } \\
\text { (conteúdo) }\end{array}$ & 12 horas & \multirow{2}{*}{$\begin{array}{l}\text { Definição e classificação dos resíduos da construção } \\
\text { civil, Gestão dos RCC nas cidades: coleta, transporte, } \\
\text { tratamento e destinação final. }\end{array}$} \\
\hline & $\begin{array}{l}\text { Atividades } \\
\text { técnica }\end{array}$ & 12 horas & \\
\hline 6. TCC & Realização & 44 horas & $\begin{array}{l}\text { Realização de um trabalho de conclusão de curso com } \\
\text { tema relacionado ao curso e, de preferência, à área de } \\
\text { atuação profissional do estudante (quando tiver). }\end{array}$ \\
\hline \multirow[t]{2}{*}{ 7. Trabalho Prático } & $\begin{array}{c}\text { Realização } \\
\text { Apresentação }\end{array}$ & 16 horas & $\begin{array}{l}\text { Apresentação de um trabalho prático (projeto) com tema } \\
\text { a ser definido. }\end{array}$ \\
\hline & & & \\
\hline
\end{tabular}

*Carga horária

Fonte: Elaborada pelos autores (2020)

Para cada componente deverá ser aberto um fórum geral de dúvidas, que será mediado pelos(as) tutores. O número de tutores dependerá do número total de alunos(as), sendo considerado um número ideal para este curso a proporção de 20 alunos(as) por tutor(a).

\section{CONSIDERAÇÕES FINAIS}

O Curso de Aperfeiçoamento em Gestão de Obras do Departamento de Engenharia Civil da UFSCar está bem consolidado em relação as atividades de ensino, pesquisa e extensão. $\mathrm{O}$ resultado é visível por meio das interações entre os docentes e os profissionais depois do período do curso. Além disso, muitos desses profissionais são estimulados a participarem do processo seletivo para o Programa de Pós-Graduação em Estruturas e Construção Civil (PPGECiv) e vários passam a cursar o programa na condição de mestrando.

Com a chegada repentina do coronavírus e a suspensão das atividades acadêmicas presenciais, os docentes foram forçados a adaptarem as práticas de ensino presencial para a modalidade online de forma emergencial. Essa mudança, que se deu de forma obrigatória, exigiu velocidade de adaptação e adoção de várias medidas. Apesar a rapidez com que as adaptações foram feitas, o curso tem atendido às expectativas dos alunos e, com isso, surgiu a ideia e possibilidade de implantação definitiva de um curso online em Gestão de Obras. Este formato se mostra uma excelente oportunidade de ampliar a oferta deste curso, que antes se dava apenas no formato presencial, para mais alunos(as), das mais variadas localidades. O custo 
mais acessível também é uma estratégia para atrair mais alunos(as) e, com isso, tornar o curso cada vez mais conhecido e reconhecido.

O objetivo deste artigo, de apresentar uma proposta de implementação deste curso na modalidade online, foi cumprido. A implantação deste curso coaduna com o aumento expressivo de cursos na modalidade $\mathrm{EaD}$, conforme apresentado no referencial teórico deste artigo. Ademais, com as novas possibilidades de ferramentas digitais e metodologias para a $\mathrm{EaD}$, este curso se torna bastante promissor. A coordenação do curso pretende, em um curto prazo, adotar metodologias ágeis para impulsionar o curso, como é o caso do rapid e-learning, que, grosso modo, é o processo de produção de conteúdo para $\mathrm{EaD}$ mais rápido do que o processo convencional, e o lean e-learning para a criação de conteúdos de treinamento mais simples, no menor tempo e com qualidade satisfatória focada no usuário final e não em efeitos visuais excessivos. Tais metodologias tem se mostrado muito propícias para o processo de ensino-aprendizagem na modalidade $\mathrm{EaD}$.

\section{REFERÊNCIAS}

ABED. Associação Brasileira de Educação a Distância. Censo EAD.BR: relatório analítico da aprendizagem a distância no Brasil 2008. São Paulo: Pearson Education do Brasil, 2010.

ABED. Associação Brasileira de Educação a Distância. Censo EAD.BR: relatório analítico da aprendizagem a distância no Brasil 2018. Curitiba: InterSaberes, 2019.

ALVES, L. Educação a distância: Conceitos e história no Brasil e no mundo. Revista Brasileira de Aprendizagem Aberta e a Distância, v.10, p. 83-92, 2011.

ANDRADE, E. P.; BRITO, G. S. X; DE OLIVEIRA, M. L. A. Aspectos cognitivos do ensino de engenharia face às exigências da competitividade e da inovação tecnológica. Disponível em: 〈http://www.neict.uff.br//docs/inova/aspectos_cognitivos.pdf>. Acesso em: 22 julho 2020.

AZAMBUJA, M. J. C.; GRIMONI, J. A. B.; CURY, L. IPTV como serviço de EaD: estudo de caso no ensino de engenharia. In: XI Congresso Brasileiro de Ensino Superior a Distância. Anais... Florianópolis, agosto, 2014.

BRASIL. INEP. Instituto Nacional de Estudos e Pesquisas Educacionais Anísio Teixeira (Inep). Censo da Educação Superior 2018: notas estatísticas: Brasília, 2019.

CASSUNDÉ, F. R.; JUNIOR, N. C. O Estado do Conhecimento Sobre Educação a Distância (EAD) em Administração: por onde caminham os artigos? Gestão e Planejamento, Salvador, v. 13, n. 2, p. 366-374, 2012.

COSTA, A. R. A educação a distância no Brasil: Concepções, histórico e bases legais. Revista Científica da FASETE, v. 1, 2017.

FREITAS, K. S. Um panorama geral sobre a história do ensino a distância. In: Araújo, B. (org). Educação a distância no contexto brasileiro: Algumas experiências da UFBA. PROGED: Universidade Federal da Bahia, 2005. 
GIOLO, J. Educação a Distância no Brasil: a expansão vertiginosa. RBPAE, v. 34, n. 1, p. 073 - 097, jan./abr., 2018.

KENSKI, V. M. Tecnologias e Ensino Presencial e a Distância. 9. ed. Campinas: Papirus, 2012.

LOURENZO, A. Qual Será o Futuro da Educação a Distância? International Journal of Business \& Marketing, v. 4, n. 2, p. 8-9, 2019.

MAIA, Carmem; MATTAR, João. ABC da EaD: a Educação a Distância hoje. São Paulo: Pearson, 2007.

MAURO, R. A.; FREITAS, R. A.; CINTRÃO, J. F. F.; GALLO, Z. Educação a Distância: Contribuições da Modalidade para uma Qualificação Empreendedora. Revista de Gestão e Projetos, v. 8, n. 3, p. 118-128, 2017.

MILES, M. B.; HUBERMAN, A. M. Qualitative data analysis: an expanded sourcebook. California: Sage, 1994.

MORAN, J. M. A educação que desejamos: novos desafios e como chegar lá. Campinas: Papirus, 2007.

PATELLA, L. O ensino a distância na engenharia: os prós e os contras. Conselho em revista. Rio Grande do Sul. Ano XI. Maio/junho. 2015

VALENTE, J. A.; MORAN, J. M.; ARANTES, V. A. (orgs). Educação a Distância: pontos e contrapontos. São Paulo: Summus, 2011.

YIN, R. K. Estudo de Caso: planejamento e métodos. 5 ed. São Paulo: Bookman, 2015.

\title{
DISTANCE EDUCATION IN CIVIL ENGINEERING: AN ONLINE TRAINING PROPOSAL IN CONSTRUCTION MANAGEMENT
}

\begin{abstract}
This paper aims to present a proposal for online formation in Construction Management, which was previously offered in persential mode and which, due to the pandemic, needed to be adapted to the new reality. The adaptation of this course to the online modality proved to be promising and, with that, the possibility of definitive implantation of the course in this format arises. It is, therefore, a case study, with a qualitative approach. It is concluded that, although the Construction Management course in the face-to-face format is consolidated, the offer of an online option brings great benefits to the recognition of this course, since it makes it more accessible, whether due to mobility or to cost, which should be less than that of the face-to-face modality.
\end{abstract}

Keywords: Distance Learning. Online training. Civil Engineering. Construction Management. 